\title{
1. Introduction: persuasive speaking and evoking political behavior
}

Ofer Feldman

\section{RHETORIC AND POLITICAL RHETORIC}

Rhetoric is the art of persuasive speaking or writing. In public speaking, it is a technique where the speaker aims to sway the minds of the listeners and influence their opinions, decisions, or actions. Political rhetoric is the use and role of persuasion in the public sphere and the political process. This includes the strategies used by political actors (or political communicators, terms that are used interchangeably in this book to refer to politicians, candidates for political office, and members of various political groups) to construct persuasive explanation and arguments in formal public debates as well as in everyday political activity. Strategies used by political actors are incorporated in speeches, statements, testimonies, legislative deliberations, filibusters, press conferences, media releases and briefings, broadcast interviews, political party manifestos and platforms, and campaign posters and advertisements that analyze, argue, or debate a particular position on any given issue. Political rhetoric is thus about using words (and pictures) to their greatest effect to bring an audience around to the speaker's political point of view, that is, to affect people's political attitudes and behavior and their political judgment and reasoning (Feldman, 2015).

Political rhetoric is a term that has come up quite often in the last few years. The emergence of a growing number of straight-talking, charismatic, and dominant leaders, especially at the helm of anti-elitist, anti-immigrant, anti-Islam populist movements across Europe, has provided excellent models of adept and effective public figures who are also skilled orators who are able to speak directly or through such social network services as Twitter and Facebook to people's needs in a manner that they are ready to hear. The current U.S. president (Donald Trump) and Israel Prime Minister (Benjamin Netanyahu, see Chapter 3 in this volume), as well as inspiring speakers in such countries as Hungary (Prime Minister Viktor Mihály Orbán), Italy (Prime Minister Giuseppe Conte and Deputy Prime Ministers Luigi Di Maio and 
Matteo Salvini), France (Marine Le Pen), the Netherlands (Geert Wilders), and the U.K. (Nigel Farage), were able to mobilize immediate popular support. Furthermore, leaders in Latin America and Southeast and East Asia, including Brazil (Jair Bolsonaro), India (Narendra Modi), Indonesia (Joko Widodo), Philippines (Rodrigo Duterte), and Japan (Abe Shinzo) demonstrated in recent elections their rhetorical ability to frame the political milieu to their citizens (and potential voters) by promising to focus on selected issues and establishing fresh agendas. These leaders, among others, have demonstrated that rhetoric appeal to both reason, by using rational, empirical arguments to frame, for example, a political situation to favor a particular 'way of seeing' it or defining uncertain circumstances about which people must make political judgments, and to emotions or tightly held beliefs, by arousing a sense of compassion, solidarity, anger, fear or even hatred, all of which affect people's political attitudes and behavior (Feldman, 2015).

This book focuses on both the rational and the emotional attributes of political rhetoric and their effect. It details theoretical and empirical dimensions of rhetoric in the interaction between political actors and the public (i.e., the electorate) in the broad context of daily affairs and political campaigning in Western societies (the U.S., U.K., France, the Netherlands, Australia, and Canada), traditional societies (Japan and China), and transitional societies (Israel and Brazil), enabling a comparison of the different structures and contents of political rhetoric used in a wide variety of societies. Two pivotal aspects are at the core of this book. The first considers the nature, content, and style of the rhetoric that is generated by politicians or candidates for political office in venues such as election campaigns, parliamentary debates, and televised interviews where public figures endeavor to appeal to (or mobilize) the (political) consciousness and behavior (support, sympathy, vote) of the public (or voters). These are either direct appeals such as in face-to-face situations when they make election speeches (as detailed in Chapters 2 and 6), or indirect appeals such as through the "regular" media (e.g., televised interviews; Chapter 8), "social" media such as Twitter and Facebook (Chapters 11 and 12, respectively), and their webpages. These appeals consist of verbal or nonverbal cues and also advertisements and posters in election campaigns (Chapters 9 and 10). The second focus is on the rhetoric's effect (or potential effect) on the behavior and attitudes of the audience, the public and voters.

\section{Content and Style}

In terms of rhetorical content and style, the most influential politicians (and their speechwriters) undoubtedly have varied motives for their choice of rhetoric to use at a particular time and place or to a given audience in the strategic pursuit of a broader political agenda. When speaking in public, they 
may screen or mask their opinions, focusing their discourse on the issues that make them feel most comfortable and competent and that are likely to lead to success. They may also avoid issues with which they are unfamiliar or which might adversely affect their political agenda or public image. They may resort to a special type of rhetoric known as crisis rhetoric to frame an issue or an occurrence as urgent and in need of a quick solution as they call for out-of-the-ordinary decisions and actions (Kiewe, 1998); use rhetoric that depicts them as experts, ultimate team leaders, or the saviors of their homeland (Montero and Rodriguez-Mora, 1998); or repeat God's name and attribute their actions to God, always presenting God as being always on "our side," supporting what "we" are doing (Abdul-Latif, 2011).

Political communicators can employ explicit and direct appeals, revealing their ideas and intentions about a range of issues and political players, at times using vulgar and offensive rhetoric. U.S. President Donald Trump's campaign and presidency has been characterized by the use of violent, racist, xenophobic, and sexist language. During his rallies and via social media, he has repeatedly called journalists the "enemy of the people," insulted women ("If Hillary Clinton can't satisfy her husband what makes her think she can satisfy America?"), and degraded immigrants, labeling Mexicans who came to the U.S. without documentation as "drug dealers, criminals, rapists" (Time, 2015). President Trump was the first presidential candidate who deviated from traditional presidential campaign norms, including courtesy, dignity, self-control, maturity, and knowledge, and instead demonstrated aggression, manipulation, crudeness and vulgarity (Krasner, 2019; also Chapter 6 in this book). President Trump has not been alone in embracing extreme and fiery language. Viktor Orbán, Prime Minister of Hungary, made a clear correlation between the illegal immigrants who are flooding into Europe and the spread of terrorism, stating that "If somebody takes masses of non-registered immigrants from the Middle East into a country, this also means importing terrorism, criminalism, anti-Semitism and homophobia" (Diekmann, 2016).

Likewise, Brazil's President Jair Bolsonaro, who has been dubbed the "Trump of the Tropics" by the Brazilian media for his extreme views, has also used violent rhetoric in many instances. These include comments on Brazil's indigenous peoples (comparing them to "animals in a zoo" and as "prehistoric men"), on women ("I'm not going to rape you, because you're very ugly"), sexual orientations and homosexuality ("I would be unable to love a gay son. I won't be a hypocrite here: I would prefer that my son die in an accident rather than appear with a [gay] moustache. For me, he would be dead"), race and immigration (Colvin and Prengaman, 2019; Fishman, 2018; Phillips, 2018). Equally, Rodrigo Duterte, the President of the Philippines, is also known for his aggressive rhetoric. At one point he said former U.S. President Barack Obama can "go to hell," called President Trump a "bigot," and referred to 
Pope Francis as "son of a whore." He talked about personally executing drug addicts, corrupted people, drug dealers, and journalists (Holcombe, 2019). Last, in an apparent intent to strengthen his image as protector of Muslims in a world hostile to them, Turkish President Recep Tayyip Erdoğan also used harsh and offensive rhetoric, warning those with anti-Muslim views (in this case, Australians and New Zealanders who plan to come to Turkey) that he would send them back "in coffins ... the way we did your grandfathers" (Fraser, 2019).

Politicians' rhetoric is affected by the political, social, and economic conditions of any given time. In Germany, for example, the change in the country's political system, especially towards the end of the 20th century, not only "changed" political rhetoric but has "turned it around" (Lang-Pfaff, 1998). Foreign policy-related rhetoric shifted after German unification, with the frequent use of new terms (e.g., "national interest" and "self-interest"), which were almost absent in earlier political speeches, and in the reinterpretation of established terms (e.g., "responsibility") (Baumann, 2002). In another example, since 2001 German political communicators have shifted their rhetoric regarding Al-Qaeda from viewing the organization as a military one to a criminal one (Hülsse and Spencer, 2008). Fear-arousing emotional appeals in the mass media made by U.S. Presidents and Prime Ministers of the U.K. and Australia correlated with changes in public attitudes and political support for government policies during the war on terrorism. Specifically, a decline in support for the leaders and increased public opposition to a desired program of action generated anger- and fear-related rhetoric (De Castella et al., 2009; De Castella and McGarty, 2011). To further illustrate, the content and style of China leaders' political rhetoric has changed, especially since 1978, following Mao Zedong's death. Subjective forms of expression have emerged, with a predominant emphasis on "science and technology." Moreover, Mao's name and the word "modernization" has almost disappeared from informal language. There has been a change in terms used to refer to intellectuals, and Chinese leaders' rhetoric has became more slogan-like, highly generic and vague, and lacking any possible visual correlations or direct examples from their own experience (Marinelli, 2013). The rhetoric of the political elite in China is discussed in Chapter 4.

In addition to political and social conditions, the venue affects political communicators' rhetoric. In Japan, for example, political figures present their views with varying degrees of openness or fuzziness, depending on the circumstances. They are more apt to disclose their genuine thoughts, honest opinions, and true intentions when talking to small groups of supporters, for example, in their home districts. Conversely, when speaking before large public gatherings, politicians' statements are carefully worded as they employ buzzwords to present the official line of their political groups. When high-echelon politicians 
in Japan publicly express rhetoric of a xenophobic or sexist nature, such as that cited above for other countries, they immediately find themselves under fire from other politicians and segments of the Japanese public. On numerous occasions, politicians have been forced to either explain their "careless" statements, apologize, or submit their resignation, even from a ministerial position (Feldman, 2004). By the same token, during televised political interviews, political communicators in Germany can demonstrate assertive and aggressive self-presentation, criticizing journalists and their questions (Schütz, 2001), and in such countries as the U.K., Taiwan, the Netherlands, and Japan, they resort to a sort of equivocating, ambiguous, and evasive communication style, in which they provide incomplete replies to questions they are asked and exploit the use of vague impressions and bland statements to channel attention to justify their policy decisions and activities and improve their political standing (Feldman and Kinoshita, 2019). The case of Japan is discussed in more detail in Chapter 8.

Whereas political communicators can use explicit and direct appeals (e.g., against immigrants and women), they may deliberately choose to utilize implicit language to convey a persuasive point by drawing on metaphors (Bull and Feldman, 2012); they can thus criticize targeted rivals groups or the media by calling them "animals" or "enemy of the people," depict terrorists as "parasites," and personify problems as enemies and imagine politics as a battle where they "fight" unemployment and inflation (Charteris-Black, 2005). In terms of style, political communicators frequently exploit slogans, catchwords, or rallying mottos. To gain acceptance of their proposals they associate their ideas with brief, memorable phrases and sound bites, employing terms such as the "the people," "the general will," "the corrupt elites," "freedom," "commitment," and "peace." Such terms and slogans elicit strong emotional responses in such countries such as Italy (Cremonesi, 2019), the Netherlands (Chapter 11), the U.S. (Chapter 2, Chapter 6, Friedman, 2017). They also appeal to the international community (Chapter 3 ).

\section{Effect of Rhetoric}

The second aspect in the book focuses on the effect of rhetoric, which is one of the more contentious issues involving political rhetoric that has evolved over the past few decades (Feldman, 2015). Methodologically speaking, as long as students of political rhetoric employ different research methods and analysis, the disagreement over how to measure and evaluate the effects of rhetoric and their significance in political attitude and behavior will remain. Indeed, it is difficult to come up with a clear conclusion on the linkages between the increasing racist, sexist, and xenophobic rhetoric of Presidents Trump, Bolsonaro, and Duterte, and Prime Minister Orbán, or that of Dutch 
politician Geert Wilders (Chapter 11), and recent instances of violence against immigrants, Muslims, or other minorities in these countries. Yet, the hatefulness of some political rhetoric clearly resonates with ordinary citizens who feel alienated or powerless in many ways. It may also help to inspire violence. Throughout history, people have committed horrific acts against each another because their attitudes were manipulated by rhetoric. One example was the inflammatory rhetoric of leaders from the Israeli right wing, who regularly labeled Prime Minister Yitzhak Rabin as a "traitor" and even a "Nazi" for wanting to make peace with the Palestinians and give back part of the Land of Israel. The rhetoric provoked passions and created a climate of divisiveness that made the assassination of Rabin possible at the hands of a right-wing assassin (Friedman, 2016).

The "Presidential address" of President Anwar Sadat of Egypt, for example, was a discourse that drew upon the religious sermon genre and quoted verses from the Qur'an. It was powerful enough to reinforce the speaker's hegemony and domination over the listeners, granting the speaker divine characteristics and taming the citizens into what has been described as servitude (Abdul-Latif, 2011). In another example, Turkish Prime Minister (at that time) Erdoğan's ability to speak like an ordinary Turkish person during the World Economic Forum in Davos in 2009 led the vast majority of Turkish society, as well as the media, to identify with his ordinary language, and 80 percent of Turks then supported Erdoğan's actions (Bayram, 2010). Similarly, Trump's simple rhetoric reinforced among the voters the idea that he was a regular person, not part of the political elite and not bound to the system. A segment of the U.S. public accepted him as he presented himself, as a new sort of leader whose vulgarity and aggression demonstrated his authenticity and his ability to handle America's problems (Chapter 6).

There was no empirical evidence that the emotional appeals employed in speeches delivered by Western leaders such as the U.S. President and the British and the Australian Prime Ministers increased perceptions of personal vulnerability in a widespread or sustained fashion. Efforts by these leaders to frighten citizens in their own countries during an international conflict have been seen as dubious for ethical, moral, and military reasons (De Castella and McGarty, 2011). As discussed in Chapter 11, populist messages in the Netherlands were found to be persuasive only for some citizens, those who feel connected to a group of victimized, relatively deprived Dutch citizens (also in Hameleers, 2019). Likewise, rhetorical devices used by political communicators have limited effects beyond the immediate invited affiliative responses (applause, laughter, and cheering) from the audience. In the case of Japan, there has been no support for the hypothesis that speakers with a higher affiliative response rate enjoy greater electoral success, measured both in terms of whether or not the candidate was elected and the proportion of votes cast. 
Neither measure correlated significantly with the overall affiliative response rate (Bull and Feldman, 2011; Feldman and Bull, 2012).

Noticeably, the persuasiveness of rhetoric in the political sphere depends not only on the nature and the style of the speech, but also on the level of trust and beliefs shared by the political speaker and the audience, and perhaps also on the way the latter perceive the former's leadership qualities and expertise, integrity, and persona. The ensuing chapters detail several of these features in a wide range of societies as they detail case studies of communicators who try to cajole, convince, and persuade their people in order to achieve their political goals.

\section{STRUCTURE OF THE BOOK}

The chapters in this book address issues relevant to political rhetoric, with special emphasis on topics and concepts that have emerged relatively recently, including rhetoric intelligences, invited behavior, political public relations, moral rhetoric, and artificial intelligence and "chatbots." These contributions employ a variety of theoretical, conceptual, and methodological approaches to examine political communicators' rhetoric based on empirical materials gathered in the U.S., Russia, the U.K., Canada, Australia, New Zealand, France, China, Israel, Brazil, the Netherlands, and Japan. As such this volume allows comparison of the different structures and contents of the rhetoric used in a variety of societies from West to East and their effect.

Chapters are clustered into three parts.

Part I is entitled "Persuasive leadership: Emotion, style, and identity in national and the international arenas." It consists of four chapters that analyze the theoretical and actual style and nature of the language employed by political communicators in domestic (e.g., the U.S., the U.K., France, and China), and international (the U.N.) fronts. In the first chapter, Carol Johnson argues that it is useful to analyze issues of gender and emotion and the close connections between them when analyzing current political discourse. Johnson analyzes the ways in which political leaders and political candidates use gendered rhetoric that mobilizes differing conceptions of heterosexual masculinity or femininity in their attempts to gain voters' support. She details in particular political communicators' (gendered) use of emotion, such as feelings of hope, fear, anger, and empathy. Johnson maintains that, while politicians often attempt to mobilize a common range of feelings in their discourse, their ability to do so can be influenced by their gender.

In Chapter 3, Michelle Stein Teer focuses on the features that make effective speeches, examining in particular the relationships between verbal and nonverbal parameters and evaluating whether leaders' self-presentations change during their leadership term. Her case studies include Israeli Prime Minister 
Benjamin Netanyahu and the U.S. President Barak Obama. She focuses on six speeches (three per leader) that these leaders delivered to the U.N. General Assemblies in 2009, 2011, and 2012. Using a qualitative-quantitative analysis of verbal and nonverbal behavioral patterns, Stein Teer decodes the leaders' speech architecture and reveals their rhetoric and cognitive profiles. Her analysis suggests that to understand the multifaceted aspects of what makes speech effective in the world of international political rhetoric, we need to gather more evidence from international and local leaders from different countries, regimes, time periods, and languages, as well as from various media platforms, such as blogs, social media, and official websites.

Chapter 4 focuses on the rhetoric of President Xi Jinping of China, the core political figure in the Chinese Communist Party and currently the most authoritative leader in the country. Drawing on database of Xi's speeches, Jianxin Wang analyses 414 speeches delivered from 2012 to 2017, differentiating among eight areas: diplomacy, society, culture, politics, economy, party building, ecology, and national defense. In his analysis, the author reveals that "socialism" is the most frequently mentioned word in $\mathrm{Xi}$ speeches and that his language style can be distinguished by his usage of numbers, figurative language, "hot" communication network buzzwords, and quotations of ancient Chinese.

In the final chapter in this section (Chapter 5), Bruno Mendelski discusses the French state of emergency in 2015-2017, focusing on its discursive and operational features from the point of view of the state's relationship with individual freedoms, in particular, those of the French Muslim minority. By considering six speeches delivered by French President François Hollande and Prime Minister Manuel Valls during the state of emergency, the author argues that the rhetoric allowed the reconstruction of the state identity in opposition to the identity of the "other," that is, the terrorist "Islamists." This rhetoric, built on a dichotomy of us (French) versus them (terrorists), enabled the French government to ensure its legitimacy and functionality as a source of security for the French society. At the same time, the author claims this process weakened democracy in France, with a significant effect on political mobilization and on how the French public views Muslims and Islam.

Part II is entitled "Evoking behavior: The rhetoric of presidential inauguration, televised interview, and election campaign." The section includes five chapters and revolves around the concept of evoking behavior, that is, the idea that political relations are better understood if considered in terms of invitations (through speeches, Twitter messages, broadcast live interviews, and election campaign advertising and posters) and responses, and that politicians take advantage of the norms associated with invitations to advance their own interests. The chapters focus on the direct/indirect and verbal/nonverbal persuasive rhetoric of politicians and candidates during inauguration addresses in 
the U.S. and Russia, televised interviews in Japan, and election campaigns in the U.S., the U.K., and Japan.

In Chapter 6, Michael Alan Krasner expands on his original concept of "invited behavior" to analyze the strategies of American party leaders and activists and the motivations and the choices of their voters. Krasner's analysis reveals how, during the 2016 election campaign, Donald Trump invited Hillary Clinton to make the election about group identity and that she accepted his invitation to her great detriment (an example of a negative invitation); how Trump invited resentful white voters to express their feelings of being slighted by unfair favoritism toward minorities and thus gained their support (a positive invitation); and how Trump was unsuccessful in 2018 in inviting the Democrats to focus on group identity, by emphasizing the "threat" posed by the "caravan" of Central American asylum seekers. Analyzing elections in this way emphasizes the interactions among competing leaders, parties, and supporters, and creates a new conceptual framework for understanding the ways in which electoral strategies are formulated and voting choices are influenced.

Chapter 7, by Albina Gayoso, investigates the inauguration speeches of U.S. President Trump in 2017 and Russian President Vladimir Putin in 2018 as examples of the use of rhetoric in two different political cultures and Political Public Relations (PPR) traditions. By employing the PPR techniques, which include both verbal and nonverbal elements of political communication, Gayoso's study expands existing rhetorical analysis to detail body language, the visual environment, data on the emotions expressed by speakers during speeches, techniques used to evoke emotions, and the effect of such techniques, including the audience's reactions. One of the important conclusions of this chapter is the need for future research on the PPR techniques to analyze videos on a number of different resources (e.g., official, local, and foreign TV channels) and compare the representation of the inauguration addresses, speakers, and the audience.

In Chapter 8, Ofer Feldman describes how leading decision-makers cope with questions posed to them during televised interview programs, and the way they endeavor to affect the content of the information conveyed to the public. The research is based on empirical data gathered and analyzed during a multi-year series of studies in Japan, and the analysis reveals two main facets at the center of broadcast political interviews: first, there is a high rate of equivocation in replies, especially by national-level politicians, who were generally asked tougher questions on important issues relative to other interviewees. Second, the culture affects the tone and content of the questions that interviewers asked (i.e., nonconflictual, open-ended, and asked in a gentle manner) as well as the reaction (calm) to the interviewees' replies. Feldman maintains that the outcome of these interactions affects not only the range of 
political information transferred to the public but also political attitudes and behavior in Japan.

In the most extensive study of its kind to date, Annemarie Walter details in Chapter 9 the extent and the ways in which British political parties made use of moral appeals in Party Election Broadcasts aired during U.K. general elections between 1983 and 2017. As Walter reports, moral rhetoric is extremely important during election campaigns because it reflects also the strategic choices of parties and thus affects voters' policy preferences and mobilization. Her multi-year examination and solid methodological approach on moral appeals enables Walter to look at the changes in political parties' use of rhetoric in political advertising, how different political parties use these appeals, what aspects of the appeals they choose to emphasize, and the reasons for differences in parties' use of moral language. Walter's study on parties' and politicians' moral rhetoric, in particular in political advertising, highlights the need to conduct similar studies in other countries to broaden the knowledge about the use of moral rhetoric and its link to political ideology across countries and time.

In Chapter 10, Masahiko Asano examines the effect of nonverbal rhetoric, in this case a candidate's smile as it appeared in campaign posters, on vote share during the 2017 lower house election to the National Diet of Japan. Employing cutting-edge face-recognition technology to measure candidates' smile, Asano discloses which political party candidates smiled most and which smiled the least, whether female candidates smiled more than male candidates, and whether new candidates smiled more than incumbent candidates. His study supports previous research in Japan and elsewhere on the relationship between smiling and electoral support, and provides new evidence suggesting that a candidate's smile has an effect on vote share, depending on the number of candidates running in a given single-member district.

Part III is entitled "Social media discourse: Populism, negative campaigns, and the use of artificial intelligence." It consists of three chapters that center on the social media in the Netherlands, Brazil, and Israel, and the role it plays, or can play, in the political process. In Chapter 11, Michael Hameleers offers a detailed analysis on the rhetoric used by Dutch right-wing populist politician Geert Wilders in his Twitter account and its effect. To better understand the language used on social media by populist politicians and how they appeal to their followers, Hameleers conducted first a qualitative content analysis of Wilders' tweets in a pre- and post-election period. Furthermore, he performed an experimental study to investigate how Wilders' direct communication may persuade the electorate. Hameleers' analysis shows that Wilders' rhetoric can be classified as prototypical for "complete" right-wing populism as he blames the corrupt elites for not solving social and economic problems. Furthermore, it reflects strong nativist and xenophobic attitudes regarding 
immigrants, Muslims, and other out-groups. Similar to Trump's discourse in the U.S., Wilders frequently attributes blame to the biased, corrupt media elites. Hameleers concludes that even though Wilders' populist discourse may be highly persuasive, populist communication does not affect people unconditionally.

Similarly, Ícaro Joathan and Jamil Marques (Chapter 12) focus on the social media and its role during the Brazilian presidential elections in 2014. The authors' particular attention is on how Facebook worked as a venue for the negative campaign sponsored by two important candidates, Dilma Rousseff and Aécio Neves. Based on content analysis and discourse analysis Joathan and Marques identified and analyzed 702 rhetorical appeals used by the candidates to attack their opponents; they explain how the use of negative campaign posts influenced the public's perception of the candidates. The authors conclude that, in general, a decision to adopt a negative campaign may have varying results, depending on the candidate, voter profiles, and the context of the election. Additional information from online campaigns in other countries and in different electoral systems would further facilitate the construction of a general model on the use of rhetoric in this regard.

In the last chapter, Chapter 13, Chen Sabag Ben-Porat and Sam Lehman-Wilzig extend their previous work on the social network to examine the question of whether social media be considered a means that provides a direct link between the public and politicians. Their chapter focuses on the way the public and parliamentary assistants, advisors, and spokespersons the intermediate group between the public and parliamentarians - perceive the future use of artificially created discourse ("chatbots"), which can mimic the parliamentarians' message and style in both written and oral forms, as a link between the politicians and the public. Based on data gathered from parliamentary assistants in the Israeli Parliament and public opinion survey, Sabag and Lehman-Wilzig found that both groups were opposed to use of these non-human machines, although not for the same reasons. Furthermore, even though a "chatbot" may be capable of mimicking the parliamentarian's pattern of thinking and communication style, the public still prefer the human parliamentary assistants. The observation that the human factor is preferable to an artificial interlocutor raises important questions on the use of artificial intelligence technology in present and future political communication.

\section{FINAL REMARK}

Taken as a whole, the contributors hope this volume provides important insights for scholars interested in the field of political rhetoric. The volume addresses an array of questions at the heart of contemporary political communication and behavior, and we hope it also serves as a useful and stim- 
ulating source to further advance the debate on the functions and role that rhetoric plays in the conduct of politics. The contributions employ a variety of theoretical, conceptual, and methodological approaches, and the chaptersindividually and collectively - highlight the need for further research and hopefully will encourage others to follow up with additional methodological tests, theoretical revisions, and case studies from other countries, and across societies and cultures.

$* * *$

I would like to express my sincerest appreciation to Harry Fabian, Commissioning Editor at Edward Elgar Publishing Ltd, Editorial Assistant Saffron Watts, Marketing Executive Sue Sharp, and Senior Desk Editor and Digital Specialist Catherine Cumming for their support and excellent assistance during the various stages of the preparation of this work. A special thank you to the copy editor Yvonne Smith for her meticulous editing. I am also indebted to each of the contributors for having undertaken their assignments with enthusiasm and with productive application of their uniquely valuable knowledge and perspectives. They have summarized some of the latest and fascinating developments in their fields of research. Finally I am very grateful for the valuable contributions of Michael Krasner, Sam Lehman-Wilzig, Hongna Miao, and Sonja Zmerli, who took part in the review process regarding the improvement of quality, coherence, and content presentation of the chapters in this volume.

\section{REFERENCES}

Abdul-Latif, E. (2011). Interdiscursivity between political and religious discourses in a speech by Sadat: Combining CDA and addressee rhetoric. Journal of Language and Politics, 10, 50-67.

Baumann, R. (2002). The transformation of German multilateralism: Changes in the foreign policy discourse since unification. German Politics and Society, 20, 1-26.

Bayram, F. (2010). Ideology and political discourse: A critical discourse analysis of Erdogan's political speech. ARECLS, 7, 23-40.

Bull, P. and Feldman, O. (2011). Invitations to affiliative audience responses in Japanese political speeches. Journal of Language and Social Psychology, 30, 158-76.

Bull, P. and Feldman, O. (2012). Theory and practice in political discourse research. In Ron Sun (ed.), Grounding social sciences in cognitive sciences (pp. 331-57), Cambridge, MA: MIT Press.

Charteris-Black, J. (2005). Politicians and rhetoric: The persuasive power of metaphor. Basingstoke: Palgrave Macmillan.

Colvin, J. and Prengaman, P. (2019). Trump buddies up with Bolsonaro, the "Trump of the Tropics." AP NEWS, 29 March. Retrieved from https://apnews.com/ bdc70648e5814d25b549d1c252910006. 
Cremonesi, C. (2019). Populism in self-directed and mediated communication: The case of the Five Star Movement in the 2013 Italian election campaign. In O. Feldman and S. Zmerli (eds), The psychology of political communicators: How politicians, culture, and the media construct and shape public discourse (pp. 99-122). New York, U.S.A. and London, U.K.: Routledge.

De Castella, K. and McGarty, C. (2011). Two leaders, two wars: A psychological analysis of fear and anger content in political rhetoric about terrorism. Analyses of Social Issues and Public Policy, 11, 180-200.

De Castella, K., McGarty, C. and Musgrove, L. (2009). Fear appeals in political rhetoric about terrorism: An analysis of speeches by Australian prime minister Howard. Political Psychology, 30, 1-26.

Diekmann, K. (2016). Hungary's prime minister says accepting Syrian refugees "also means importing terrorism, criminalism anti-Semitism and homophobia." Business Inside, 25 February. Retrieved from https://www.businessinsider.com/viktor-orban -interview-refugee-migrant-hungary-2016-2.

Feldman, O. (2004). Talking politics in Japan today. Brighton, UK: Sussex Academic Press.

Feldman, O. (2015). Politische Rhetorik [Political rhetoric]. In S. Zmerli and O. Feldman (eds), Politische Psychologie: Handbuch für Studium und Wissenschaft [Political psychology: Handbook for study and science] (pp. 201-17). Baden-Baden, Germany: Nomos.

Feldman, O. and Bull, P. (2012). Understanding audience affiliation in response to political speeches in Japan. Language \& Dialogue, 3, 375-97.

Feldman, O. and Kinoshita, K. (2019). Political communicators and control in political interviews in Japanese television: A comparative study and the effect of culture. In O. Feldman and S. Zmerli (eds), The psychology of political communicators: How politicians, culture, and the media construct and shape public discourse (pp. 31-55). New York, U.S.A. and London, U.K.: Routledge.

Fishman, A. (2018). Jair Bolsonaro is elected president of Brazil: Read his extremist, far-right positions in his own words. The Intercept, 29 October. Retrieved from https://theintercept.com/2018/10/28/jair-bolsonaro-elected-president-brazil/.

Fraser, S. (2019). Turkey's Erdogan sparks spat with Australia, New Zealand. Associated Press, 21 March. Retrieved from https://www.hawaiitribune-herald .com/2019/03/21/nation-world-news/turkeys-erdogan-sparks-spat-with-australia -new-zealand/.

Friedman, T. (2016). A country's leader assassinated, spurred by rhetoric. The Seattle Times, 10 August. Retrieved from https://www.seattletimes.com/opinion/a-countrys -leader-assassinated-spurred-by-rhetoric/.

Friedman, U. (2017). What is a populist? And is Donald Trump one? The Atlantic, 27 February. Retrieved from https://www.theatlantic.com/international/archive/2017/ 02/what-is-populist-trump/516525/.

Hameleers, M. (2019). They caused our crisis! The contents and effects of populist communication: Evidence from the Netherlands. In O. Feldman and S. Zmerli (eds), The psychology of political communicators: How politicians, culture, and the media construct and shape public discourse (pp. 79-98). New York, U.S.A. and London, U.K.: Routledge.

Holcombe, H. (2019). "I'd be happy to slaughter them": Philippine President Rodrigo Duterte's most outrageous statements. CBS News, 30 June. Retrieved from https:// www.cbsnews.com/news/rodrigo-duterte-most-outrageous-statements-cbsn -originals/. 
Hülsse, R. and Spencer, A. (2008). The metaphor of terror: Terrorism studies and the constructivist turn. Security Dialogue, 39, 571-92.

Kiewe, A. (1998). The crisis tool in American political discourse. In O. Feldman and C. De Landtsheer (eds), Politically speaking: A worldwide examination of language used in the public sphere (pp. 79-90). Westport, CT: Greenwood Press.

Krasner, M.A. (2019). The new American electoral politics: How invited behavior and reality TV explain Donald Trump's victory. In O. Feldman and S. Zmerli (eds), The psychology of political communicators: How politicians, culture, and the media construct and shape public discourse (pp. 13-30). New York, U.S.A. and London, U.K.: Routledge.

Lang-Pfaff, C. (1998). The changing political language of Germany. In O. Feldman and C. De Landtsheer (eds), Politically speaking: A worldwide examination of language used in the public sphere (pp. 31-42). Westport, CT: Greenwood Press.

Marinelli, M. (2013). Jiang Zemin's discourse on intellectuals: The political use of formalised language and the conundrum of stability. Journal of Current Chinese Affairs, 42, 111-40.

Montero, M. and Rodriguez-Mora, I. (1998). Discourse as a stage for political actors: An analysis of presidential addresses in Argentina, Brazil, and Venezuela. In O. Feldman and C. De Landtsheer (eds), Politically speaking: A worldwide examination of language used in the public sphere (pp. 91-105). Westport, CT: Greenwood Press.

Phillips, T. (2018). Trump of the tropics: the "dangerous" candidate leading Brazil's presidential race. The Guardian, 19 April. Retrieved from https://www.theguardian .com/world/2018/apr/19/jair-bolsonaro-brazil-presidential-candidate-trump -parallels.

Schütz, A. (2001). Self-presentation of political leaders in Germany: The case of Helmut Kohl. In O. Feldman and L.O. Valenty (eds), Profiling political leaders: Cross cultural studies of personality and behavior (pp. 217-32). Westport, CT: Greenwood Press.

Time (2015). Here's Donald Trump's presidential announcement speech. Time, 16 June. Retrieved from https://time.com/3923128/donald-trump-announcement-speech/. 